\title{
Regional Differences in the Prevalence of Anaemia and Associated Risk Factors among Infants Aged 0-23 Months in China: China Nutrition and Health Surveillance
}

\author{
Shujuan Li ${ }^{1,2}$, Yacong Bo ${ }^{3}$, Hongyan Ren ${ }^{2}{ }^{\oplus}$, Chen Zhou ${ }^{1}$, Xiangqian Lao ${ }^{3}$, Liyun Zhao ${ }^{1}$ and Dongmei Yu ${ }^{1, *}$ \\ 1 National Institute for Nutrition and Health, Chinese Center for Disease Control and Prevention, \\ Beijing 100050, China; lisj@ninh.chinacdc.cn (S.L.); zc983702782@163.com (C.Z.); \\ zhaoly@ninh.chinacdc.cn (L.Z.) \\ 2 State Key Laboratory of Resources and Environmental Information System, Institute of Geographic Sciences \\ and Natural Resources Research, Chinese Academy of Sciences, Beijing 100101, China; renhy@lreis.ac.cn \\ 3 Jockey Club School of Public Health and Primary Care, the Chinese University of Hong Kong, \\ Hong Kong SAR 999077, China; boyacong777@gmail.com (Y.B.); xqlao@cuhk.edu.hk (X.L.) \\ * Correspondence: yudm@ninh.chinacdc.cn
}

Citation: Li, S.; Bo, Y.; Ren, H.; Zhou, C.; Lao, X.; Zhao, L.; Yu, D. Regional Differences in the Prevalence of Anaemia and Associated Risk Factors among Infants Aged 0-23 Months in China: China Nutrition and Health Surveillance. Nutrients 2021, 13, 1293. https://doi.org/10.3390/nu13041293

Academic Editor: Ekhard E. Ziegler

Received: 3 March 2021

Accepted: 8 April 2021

Published: 14 April 2021

Publisher's Note: MDPI stays neutral with regard to jurisdictional claims in published maps and institutional affiliations.

Copyright: (c) 2021 by the authors. Licensee MDPI, Basel, Switzerland. This article is an open access article distributed under the terms and conditions of the Creative Commons Attribution (CC BY) license (https:// creativecommons.org/licenses/by/ $4.0 /)$

\begin{abstract}
Infantile anaemia has been a severe public health problem in China for decades. However it is unclear whether there are regional differences in the prevalence of anaemia. In this study, we used data from the China Nutrition and Health Surveillance (CNHS) to assess the prevalence of anaemia and the risk factors associated with its prevalence in different regions. We included 9596 infants aged 0-23 months from the CNHS 2013 database. An infant was diagnosed with anaemia if he/she had a haemoglobin concentration of $<110 \mathrm{~g} / \mathrm{L}$. We used multivariate logistic regression to investigate the potential risk factors associated with the development of anaemia. We found that anaemia was present in $2126(22.15 \%)$ of the infants assessed. Approximately $95 \%$ of these cases were classified as mild anaemia. Based on the guidelines laid out by the World Health Organization, 5.5\% and 43.6\% of the surveillance sites were categorized as having severe and moderate epidemic levels of anaemia, respectively. The prevalence of infantile anaemia in Eastern, Central and Western China was 16.67\%, $22.25 \%$ and $27.44 \%$, respectively. Premature birth, low birth weight, breastfeeding and residence in Western China were significantly associated with higher odds of developing anaemia. Female sex and having mothers with high levels of education and maternal birth age $>25$ years were associated with lower odds of developing anaemia. In conclusion, we observed significant regional disparities in the prevalence of infantile anaemia in China. Western China had the highest prevalence of infantile anaemia, and rural regions showed a higher prevalence of anaemia than urban regions.
\end{abstract}

Keywords: anaemia; 0-23-month-old infants; regional differences; risk factors; China

\section{Introduction}

Anaemia, which affects approximately 1.62 billion $(24.8 \%)$ people worldwide, is a global public health problem. It can occur at any stage of life but is more prevalent in children aged $<5$ years and especially in children aged $<2$ years [1]. Notably, during the first 1000 days of life, the brain is particularly vulnerable to psychosocial, environmental and biological factors. This phase is critical to the healthy development of children [2]. As such, the adverse effects of anaemia on brain development during this period are irreversible, even if anaemia is corrected during later stages of childhood [3].

The prevalence of infantile anaemia has been examined in some regions of China [4-6], but at relatively small scales, and there are few data that are representative of the entire country. In addition, the prevalence of childhood anaemia may differ with region, maternal anaemia status and socioeconomic status [7]. Few studies have evaluated regional disparities in infantile anaemia prevalence, especially between urban and rural areas. As infants under two years of age grow and develop rapidly, an age difference of mere months may 
affect their degree of anaemia and other associated factors. These associations need to be investigated in further detail.

The National Nutrition Plan (2017-2030) of China mandates that the anaemia rate in children under five years be reduced to $<10 \%$ by 2030 . To achieve this goal, it is necessary to map the prevalence of infantile anaemia across the country and identify areas of high anaemia prevalence. In this study, we analysed infant data from the China Nutrition and Health Surveillance (CNHS) database to determine the national and regional prevalence of infantile anaemia, based on the measurement of infants' haemoglobin $(\mathrm{Hb})$ concentrations. We also explored the potential factors associated with a high prevalence of infantile anaemia.

\section{Materials and Methods}

\subsection{Study Design and Participants}

The CNHS (2010-2013) was a national cross-sectional study with representative participants covering 31 provinces, municipalities as well as autonomous regions of China. It was conducted by the National Institute for Nutrition and Health, the Chinese Centre for Disease Control and Prevention. In 2013, a multistage stratified cluster sampling method was used to investigate the nutritional status of children aged $0-5$ years and that of lactating mothers across the entire country. Fifty-five surveillance sites (cities/districts/counties) were selected, based on the principle of representation [8]; that is, three towns and three village-neighbourhood committees were selected randomly from each surveillance site. If the population size of the selected neighbourhood committee was less than the required sample size, it was increased as required. All of the children's parents (or other caregivers) were asked to sign an informed consent form prior to joining the study. The protocol for this study was approved by the Ethics Committee of the National Institute for Nutrition and Food Safety of the Chinese Centre for Disease Control and Prevention (No. 2013-018).

As shown in Figure 1, 11,779 infants aged 0-23 months for whom $\mathrm{Hb}$ concentration measurements were available were initially included. We excluded 2,183 infants, as they were missing information on maternal characteristics $(n=497)$ or feeding status $(n=1686)$. Finally, 9596 infants were included in our analysis. Of these, 2959 infants were aged 0-5 months, 3185 were aged 6-11 months and 3452 were aged $12-23$ months.

\subsection{Data Collection}

The CNHS adopted a structured questionnaire to collect detailed information on a broad range of factors. The following information was used in the present study: demographic factors (infant's age, sex, ethnicity, mother's age), socioeconomic status (mother's level of education, family income and type of toilet used in the household), status of premature birth, infant's birth weight and infant's feeding status (whether breastfeeding and if so, the duration of breastfeeding).

A diet survey was conducted to collect information on the infants' minimum dietary diversity (MDD). Based on the guidelines laid out by the World Health Organization (WHO), an infant was defined as meeting the MDD if he/she received four or more groups from the following seven groups of food: (1) cereals and rhizomes, (2) beans, (3) milk and dairy products, (4) meat (animal liver and meat), (5) eggs, (6) fruits and vegetables rich in vitamin A (food that is yellow on the inside, and/or any dark green leafy vegetables) and (7) any other vegetables and fruits. We also collected information on whether the infant received any iron-rich foods or iron supplements in the $24 \mathrm{~h}$ preceding the survey.

We collected blood samples from the fingers of the infants and evaluated the $\mathrm{Hb}$ concentration using the cyanide high-iron method [9]. Infants living at altitudes $<1000 \mathrm{~m}$ above sea level were diagnosed with anaemia when their $\mathrm{Hb}$ concentration was $<110 \mathrm{~g} / \mathrm{L}$. Infants with a $\mathrm{Hb}$ concentration of $90-110 \mathrm{~g} / \mathrm{L}$ were diagnosed as having mild anaemia and those with a $\mathrm{Hb}$ concentration of $<90 \mathrm{~g} / \mathrm{L}$ were diagnosed as having moderate or severe anaemia. For those living at altitudes $>1000 \mathrm{~m}$ above sea level, the thresholds were adjusted based on the following formula: 
$\mathrm{Hb}$ adjustment $=-0.032 \times($ altitude $\times 0.0032808)+0.022 \times($ altitude $\times 0.0032808)[10]$.

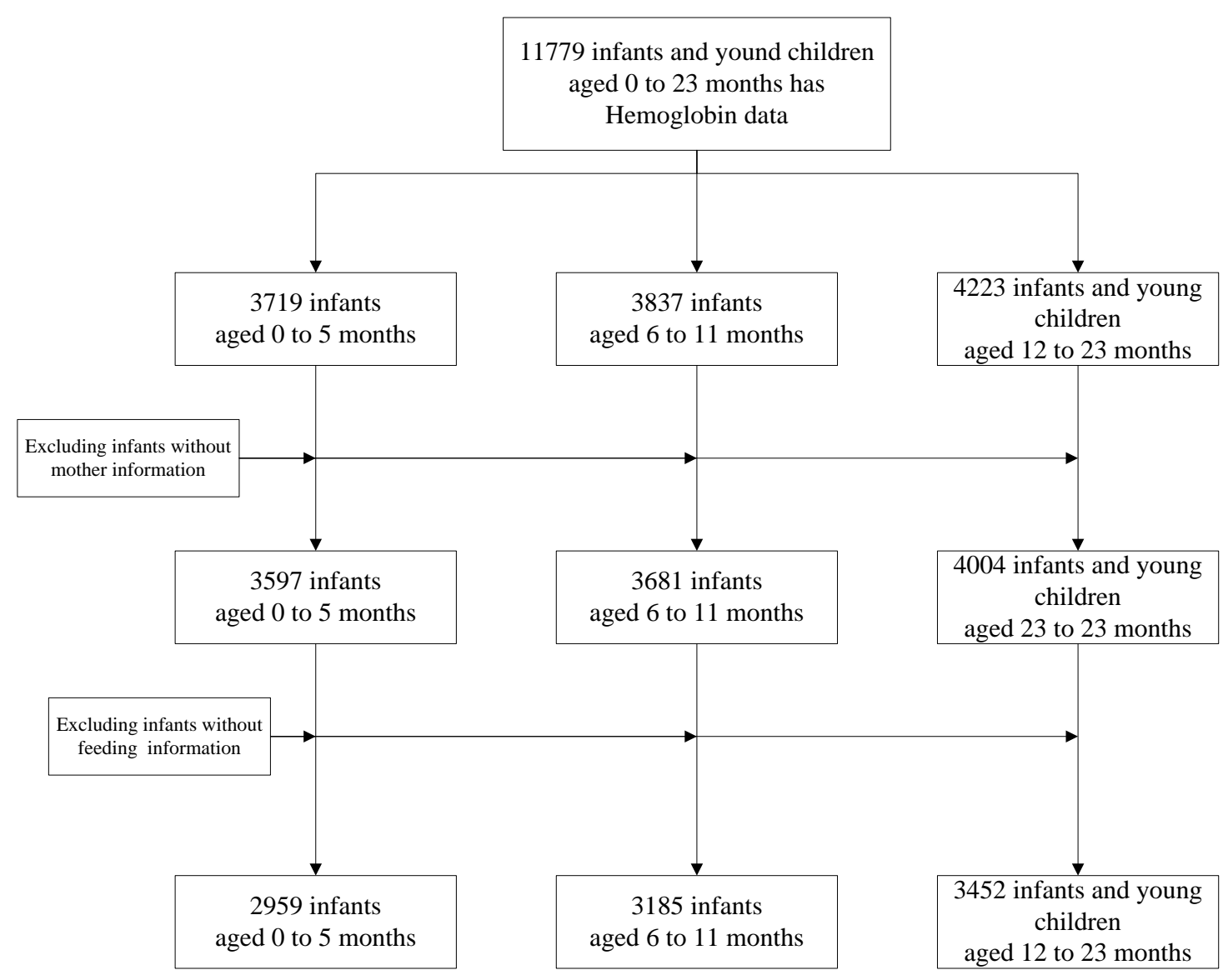

Figure 1. Flowchart of study procedures.

\subsection{Statistical Analysis}

SAS v9.4 software was used for statistical analyses. $\mathrm{Hb}$ level was calculated with the "Surveymeans" procedure and tested with the Wilcoxon test, and anaemia prevalence was calculated with the "Surveyfreq" procedure. We first calculated the overall and sex-specific concentrations of $\mathrm{Hb}$ and the prevalence of anaemia. We then classified the participants as rural or urban residents, based on the code for statistical division and code for urban rural division in 2012 from the National Bureau of Statistics of China [11], and calculated the rural and urban $\mathrm{Hb}$ concentrations and anaemia prevalence. Finally, we grouped the participants into three groups according to geographical region, namely Eastern, Central and Western regions (Figure 2A), in accordance with the China Health Statistical Yearbook [12]. The corresponding concentrations of $\mathrm{Hb}$ and prevalence of anaemia were then calculated for each region. 


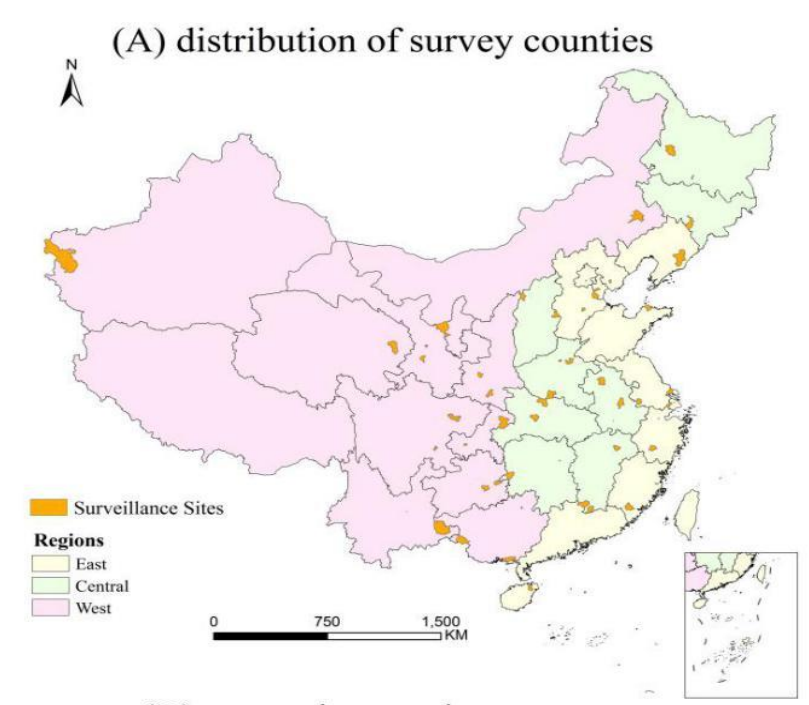

(D) anaemia prevalence among

$\AA$ infants aged $0-5$ months

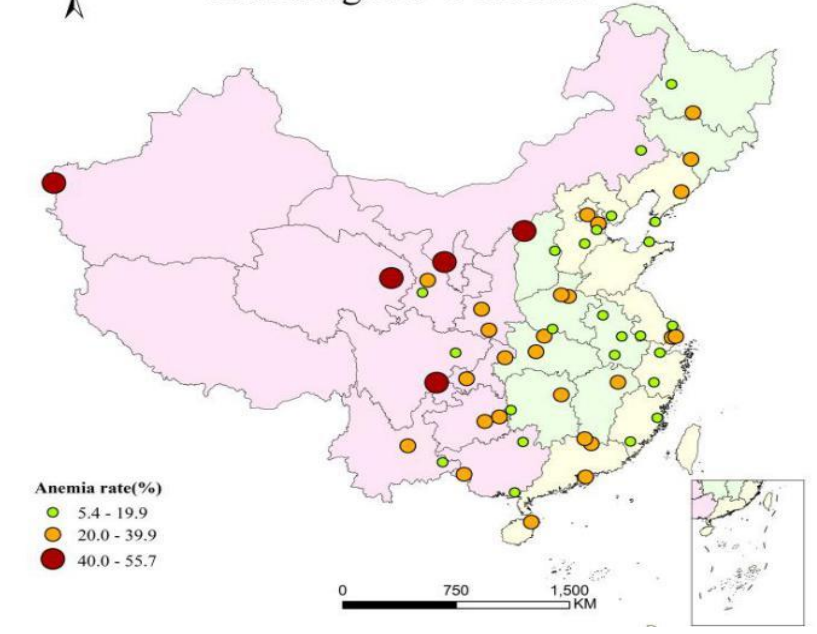

(B) distribution of $\mathrm{Hb}$ mean values

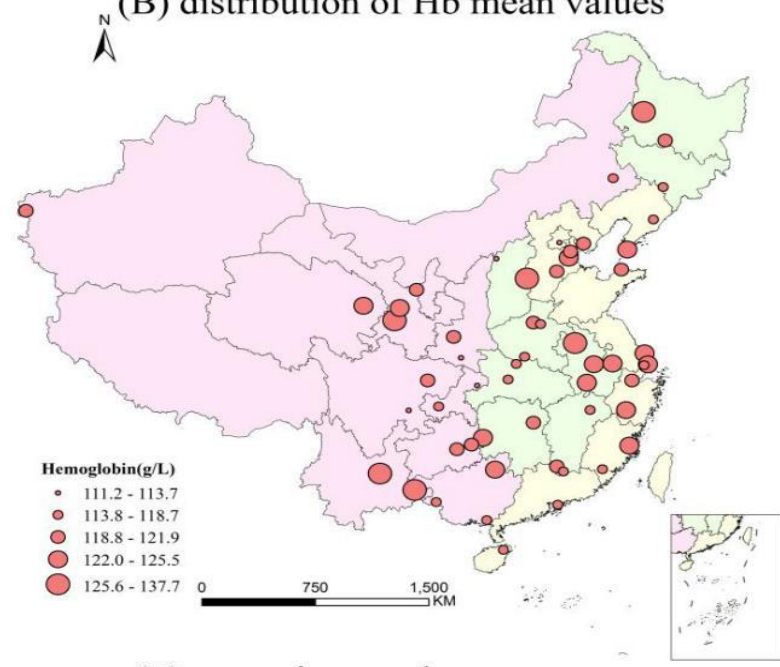

(E) anaemia prevalence among

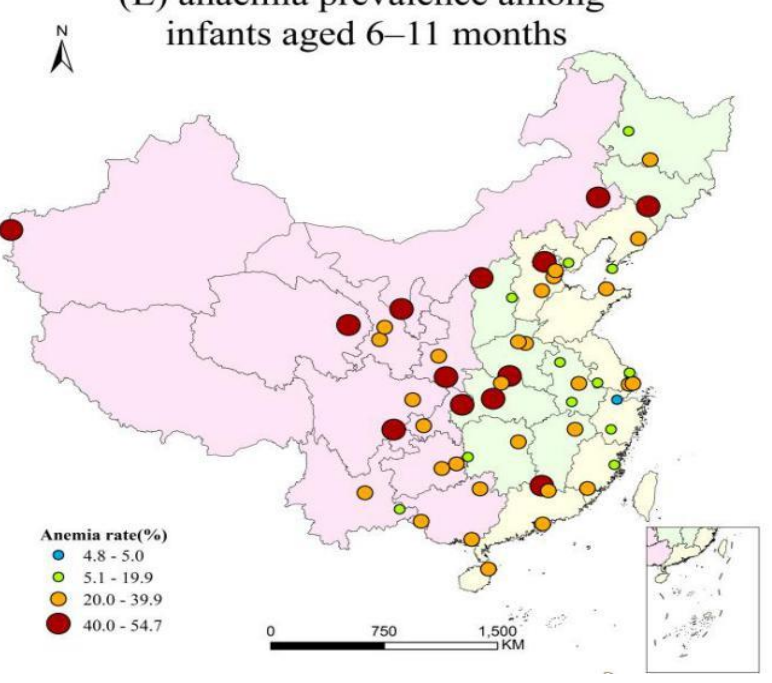

(C) total anaemia prevalence

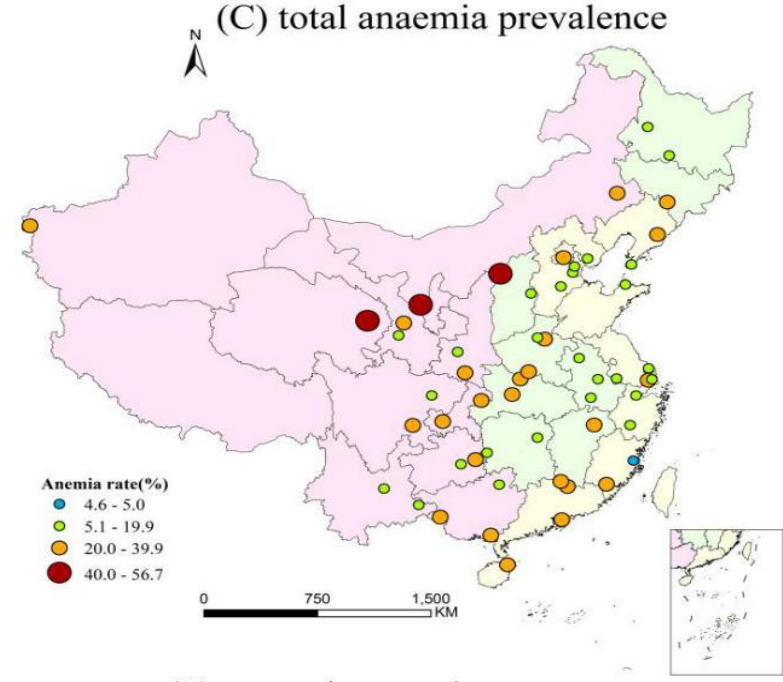

(F) anaemia prevalence among

A infants aged 12-23 months

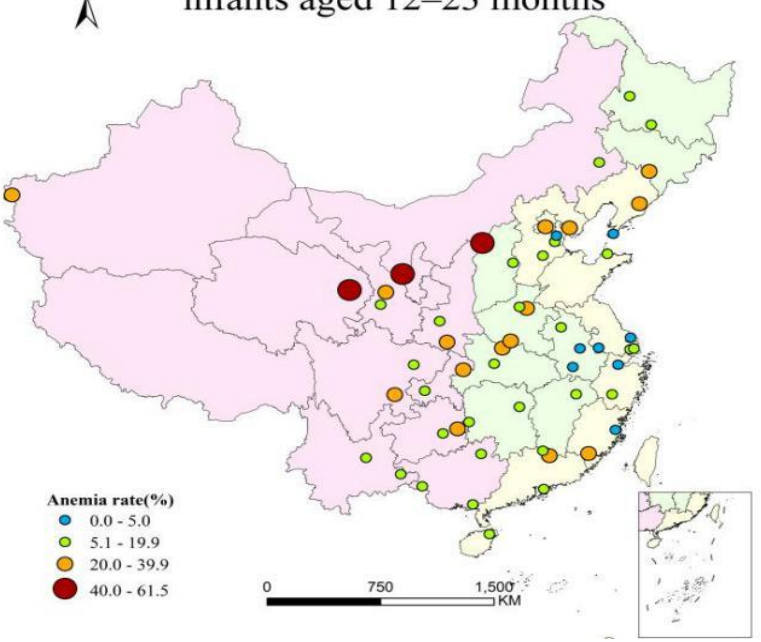

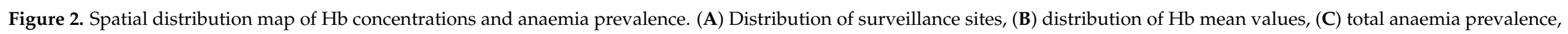
(D) anaemia prevalence among infants aged 0-5 months, (E) anaemia prevalence among infants aged 6-11 months and (F) anaemia prevalence among infants aged 12-23 months. 
We used a multivariate logistic regression model to explore the potential risk factors associated with the prevalence of anaemia. A stepwise method of variables entry was used. We conducted a literature review of the published literature pertaining to potential predictors/risk factors associated with the development of anaemia and considered the following factors: age (months), sex (male vs. female); ethnicity (Han Chinese vs. non-Han Chinese); premature birth (yes vs. no); low birth weight (LBW; yes vs. no); maternal age ( $\leq 25$ years vs. $>25$ years); MDD (yes vs. no); intake of iron-rich food or iron supplements (yes vs. no); level of mother's education (>secondary school vs. <secondary school); family income ( $<$ RMB35,000 vs. $\geq$ RMB35,000); toilet type (sanitary vs. unsanitary; sanitary toilet refers to one with water-flushing facilities and/or a dry toilet), regional socioeconomic status, as defined by the central government big city (BC) referred to the central urban areas with a population of more than 1 million municipalities directly under the central government, cities under separate planning and provincial capital cities; small or mediumsized city (SMC) referred to all the districts and county-level cities outside the central urban areas of the above-mentioned big cities and the county-level cities or districts among the 592 poverty-stricken counties; poverty-stricken county (PC), county-level cities or districts are removed from the 592 counties identified in the "2001-2010 national program for poverty alleviation and development in rural areas"; or ordinary county (OC), counties except PC); residential area (urban vs. rural); and geographical region (Eastern, Central and Western). A two-tailed $p$-value of $p<0.05$ was considered to indicate statistical significance.

\section{Results}

\subsection{General Characteristics of the Participants}

Table 1 summarises the characteristics of the included infants and their mothers. Of the 9596 infants, slightly more than half (51.28\%) were male. Most of the infants belonged to the Han ethnic group (86.08\%) and were term births (89.08\%). Most of the mothers had an educational level of high school or lower and were aged 25 years or older at the birth of their infants.

Table 1. Sample status of infants and young children.

\begin{tabular}{ccc}
\hline Characteristic & $N$ & Percentage (\%) \\
\hline Age & & \\
\hline $0-5$ months old & 2959 & 30.84 \\
$6-11$ months old & 3185 & 33.19 \\
$12-23$ months old & 3452 & 35.97 \\
\hline Sex & & \\
\hline Male & 4921 & 51.28 \\
Female & 4675 & 48.72 \\
\hline Ethnicity & & 86.08 \\
\hline Han & 8260 & 12.05 \\
Other & 1156 & 1.87 \\
Unknown & 180 & \\
\hline Premature birth & & 89.92 \\
\hline Yes & 1048 & \\
No & 8548 & 3.42 \\
\hline LBW & & 96.58 \\
\hline Yes & 328 & \\
No & 9268 & \\
\hline
\end{tabular}


Table 1. Cont.

\begin{tabular}{|c|c|c|}
\hline Characteristic & $N$ & Percentage $(\%)$ \\
\hline \multicolumn{3}{|l|}{ Socioeconomic status } \\
\hline $\mathrm{BC}$ & 1967 & 20.50 \\
\hline SMC & 2848 & 29.68 \\
\hline OC & 3019 & 31.46 \\
\hline PC & 1762 & 18.36 \\
\hline \multicolumn{3}{|l|}{ Regional division } \\
\hline Eastern region & 2993 & 31.19 \\
\hline Central region & 3219 & 33.55 \\
\hline Western region & 3384 & 35.26 \\
\hline \multicolumn{3}{|l|}{ Family status } \\
\hline \multicolumn{3}{|l|}{ Family income } \\
\hline$<$ RMB35,000 & 7676 & 79.99 \\
\hline$\geq$ RMB35,000 & 1051 & 10.95 \\
\hline No answer & 869 & 9.06 \\
\hline \multicolumn{3}{|l|}{ Toilet type } \\
\hline Sanitary & 6065 & 63.20 \\
\hline Unsanitary & 3528 & 36.77 \\
\hline Unknown & 3 & 0.03 \\
\hline \multicolumn{3}{|l|}{ Maternal status } \\
\hline \multicolumn{3}{|l|}{ Education level } \\
\hline High school and below & 7507 & 78.24 \\
\hline College or above & 2088 & 21.76 \\
\hline Unknown & 1 & 0.00 \\
\hline \multicolumn{3}{|l|}{ Maternal age } \\
\hline 25 years old and under & 2893 & 30.15 \\
\hline Over 25 years old & 6703 & 69.85 \\
\hline \multicolumn{3}{|c|}{ Feeding status of 6-23-month-old infants } \\
\hline \multicolumn{3}{|l|}{ Meet MDD } \\
\hline Yes & 3376 & 50.87 \\
\hline No & 3261 & 49.13 \\
\hline \multicolumn{3}{|l|}{ Iron fortification } \\
\hline Yes & 2975 & 44.82 \\
\hline No & 3662 & 55.18 \\
\hline
\end{tabular}

LBW: low birth weight; BC: big city; SMC: small or medium-sized city; OC: ordinary county; PC: poverty-stricken county; MDD: minimum dietary diversity.

\subsection{Hb and Anaemia Status}

\subsection{1. $\mathrm{Hb}$ Status}

As shown in Table 2, the mean $\mathrm{Hb}$ concentrations were $120.44 \pm 0.77 \mathrm{~g} / \mathrm{L}, 120.96 \pm$ $0.84 \mathrm{~g} / \mathrm{L}, 120.23 \pm 0.73 \mathrm{~g} / \mathrm{L}$ and $120.97 \pm 1.22 \mathrm{~g} / \mathrm{L}$ for male infants, female infants, infants living in urban areas and those living in rural areas, respectively. In addition, the $\mathrm{Hb}$ concentrations were slightly higher in infants aged 12-23 months across all subgroups.

The spatial distribution of the 55 selected surveillance sites is depicted in Figure 2A. Due to the relatively small population in the Western region, we monitored fewer surveillance sites in this region than in the Eastern region. The $\mathrm{Hb}$ concentrations of infants in the Central region were slightly higher than those in the Western and Eastern regions (Figure 2B). 
Table 2. Haemoglobin status of infants stratified by sex, residential area and geographical region.

\begin{tabular}{|c|c|c|c|c|c|c|c|c|}
\hline \multirow{2}{*}{ Months } & \multicolumn{2}{|c|}{$0-5$} & \multicolumn{2}{|c|}{$6-11$} & \multicolumn{2}{|c|}{$12-23$} & \multicolumn{2}{|c|}{ Total } \\
\hline & Mean & SE & Mean & SE & Mean & SE & Mean & SE \\
\hline All & $119.57^{\mathrm{a}}$ & 0.83 & $117.18^{a}$ & 0.92 & $122.72^{a}$ & 0.81 & 120.67 & 0.79 \\
\hline \multicolumn{9}{|l|}{ Sex } \\
\hline Male & 119.18 & 0.83 & 116.83 & 0.90 & 122.59 & 0.82 & $120.44 *$ & 0.77 \\
\hline Female & 120.04 & 0.90 & 117.59 & 0.99 & 122.89 & 0.84 & $120.96^{*}$ & 0.84 \\
\hline \multicolumn{9}{|c|}{ Residential area } \\
\hline Urban & $118.20 *$ & 0.71 & 116.81 & 0.87 & 122.51 & 0.88 & $120.23 *$ & 0.73 \\
\hline Rural & 120.49 * & 1.31 & 117.40 & 1.39 & 122.87 & 1.22 & 120.97 * & 1.22 \\
\hline \multicolumn{9}{|c|}{ Geographical region } \\
\hline Eastern & $118.90 *$ & 0.69 & $116.83 *$ & 0.82 & 123.02 & 0.86 & $120.62 *$ & 0.71 \\
\hline Central & 120.46 * & 1.99 & 118.43 * & 2.14 & 122.52 & 1.68 & 121.03 * & 1.75 \\
\hline Western & $119.28 *$ & 1.24 & 116.13 * & 1.23 & 122.63 & 1.49 & 120.36 * & 1.37 \\
\hline
\end{tabular}

SE: standard error. Wilcoxon test results: ${ }^{a}$ represented significant difference among different month age * represented significant difference among sex, residential area or geographical region within one month age group or all infants.

\subsubsection{Prevalence of Anaemia in Infants}

In 2013, the overall anaemia prevalence in Chinese infants aged 0-23 months was $22.15 \%$, with $95.3 \%$ of the affected infants having mild anaemia and $4.7 \%$ having moderate anaemia. There were no recorded cases of severe anaemia. Anaemia was more prevalent in male infants $(23.14 \%)$ than in female infants $(20.96 \%)$. The prevalence of anaemia among infants living in rural areas $(23.57 \%)$ was higher than that in infants living in urban areas (20.02\%). Similarly, infants aged 6-11 months (30.64\%) were more likely to have anaemia than those aged $0-5$ months $(25.30 \%)$ or $12-23$ months (16.97\%). Moreover, the prevalence of anaemia in the Eastern region (16.67\%; 95\% confidence interval (CI): 15.50-17.84) was significantly lower than that in the Central (22.25\%; 95\% CI: 20.88-23.63) and Western regions (27.44\%; 95\% CI: 25.93-28.95). Further details are given in Table 3.

Table 3. Anaemia status of infants stratified by sex, residential area and geographical region.

\begin{tabular}{|c|c|c|c|c|c|c|c|c|}
\hline \multirow{2}{*}{ Months } & \multicolumn{2}{|c|}{$0-5$} & \multicolumn{2}{|c|}{$6-11$} & \multicolumn{2}{|c|}{$12-23$} & \multicolumn{2}{|c|}{ Total } \\
\hline & $N(\%)$ & $95 \%$ CI & $N(\%)$ & $95 \% \mathrm{CI}$ & $N(\%)$ & $95 \%$ CI & $N(\%)$ & $95 \% \mathrm{CI}$ \\
\hline All & $944(25.30)$ & $23.87-26.74$ & $1151(30.64)$ & $29.13-32.15$ & 16.97 & $15.83-18.12$ & $2798(22.15)$ & $21.36-22.94$ \\
\hline \multicolumn{9}{|l|}{ Sex } \\
\hline Male & $511(26.87)$ & $24.82-28.92$ & $640(32.73)$ & $30.60-34.86$ & $381(17.28)$ & $15.70-18.87$ & $1532(23.14)$ & $22.04-24.25$ \\
\hline Female & $433(23.48)$ & $21.48-25.48$ & $511(28.15)$ & $26.03-30.27$ & $322(16.60)$ & $14.93-18.26$ & $1266(20.96)$ & $19.83-22.09$ \\
\hline \multicolumn{9}{|c|}{ Residential area } \\
\hline Urban & $504(26.05)$ & $24.09-28.01$ & $536(27.99)$ & $25.98-30.00$ & 279 (14.17) & $12.62-15.71$ & $1319(20.02)$ & $18.95-21.09$ \\
\hline Rural & $440(24.80)$ & $22.80-26.82$ & $615(32.27)$ & $30.17-34.37$ & $424(18.92)$ & 17.30-20.55 & 1479 (23.57) & $22.47-24.68$ \\
\hline \multicolumn{9}{|c|}{ Geographical location } \\
\hline Eastern & $290(20.88)$ & $18.68-23.09$ & $344(25.17)$ & $22.80-27.54$ & $162(11.12)$ & $9.49-12.75$ & $796(16.67)$ & $15.50-17.84$ \\
\hline Central & $289(24.19)$ & $21.71-26.66$ & $364(28.95)$ & $26.39-31.50$ & $249(18.21)$ & $16.16-20.27$ & $902(22.25)$ & $20.88-23.63$ \\
\hline Western & $365(30.97)$ & $28.25-33.70$ & $443(37.96)$ & $35.11-40.80$ & $292(21.42)$ & $19.23-23.61$ & $1100(27.44)$ & 25.93-28.95 \\
\hline
\end{tabular}

CI: confidence interval.

The spatial distribution of the prevalence of anaemia is presented in Figure $2 \mathrm{C}-\mathrm{F}$. The WHO classifies a site with an anaemia detection rate of $\geq 40 \%$ as having a severe epidemic, a site with a rate of $20.0-39.9 \%$ as having a moderate epidemic, a site with a rate of $5.0-19.9 \%$ as having a mild epidemic and a site with a rate of $\leq 4.9 \%$ as normal [13]. 
Thus, of the 55 surveillance sites selected for this study, 3 had a severe epidemic, 24 had a moderate epidemic, 27 had a mild epidemic and 1 was under a normal epidemic level. The prevalence of anaemia across all 55 sites ranged from 4.58 to $56.70 \%$, with the highest prevalence in the Western region, followed by those in the Central and Eastern regions (Figure 2C). Figure 2D-F shows the prevalence of anaemia stratified by the age groups.

\subsection{Factors Associated with the Prevalence of Anaemia in Infants Aged 0-23 Months}

Table 4 shows the factors associated with the prevalence of anaemia in infants aged 0-23 months, derived from multivariate logistic regression analyses. For infants aged $<6$ months, female sex (odds ratio $(\mathrm{OR})=0.80 ; 95 \%$ CI: $0.68-0.95 ; p=0.01$ ) and having a mother with a higher level of education ( $\mathrm{OR}=0.77 ; 95 \%$ CI: $0.63-0.95 ; p=0.01)$ were associated with lower odds of developing anaemia. In contrast, premature birth $(\mathrm{OR}=1.38$; 95\% CI: 1.06-1.81; $p=0.02)$, LBW (OR $=1.99 ; 95 \%$ CI: 1.28-3.09; $p=0.00)$, breastfeeding $(\mathrm{OR}=1.34 ; 95 \% \mathrm{CI}: 1.04-1.72 ; p=0.02)$ and residing in the Western region of China $(\mathrm{OR}=1.66 ; 95 \% \mathrm{CI}: 1.35-2.04 ; p<0.01)$ were associated with higher odds of developing anaemia.

Table 4. Factors associated with anaemia among children aged 0-23 months, based on multivariate logistic regression analyses.

\begin{tabular}{|c|c|c|c|c|c|c|c|}
\hline \multirow{2}{*}{ Influence Factor } & \multirow{2}{*}{ Reference } & \multicolumn{2}{|c|}{ 0-5 Months } & \multicolumn{2}{|c|}{ 6-11 Months } & \multicolumn{2}{|c|}{ 12-23 Months } \\
\hline & & OR (95\% CI) & $p$ & OR $(95 \%$ CI) & $p$ & OR $(95 \%$ CI) & $p$ \\
\hline \multicolumn{8}{|l|}{ Sex } \\
\hline Female & Male & $0.80(0.68-0.95)$ & 0.01 & $0.77(0.66-0.90)$ & 0.00 & NS & \\
\hline \multicolumn{8}{|l|}{ Premature } \\
\hline \multirow{2}{*}{\multicolumn{8}{|c|}{$\begin{array}{l}\text { Yes } \\
\text { Low birth weight }\end{array}$}} \\
\hline & & & & & & & \\
\hline Yes & No & $1.99(1.28-3.09)$ & 0.00 & NS & & NS & \\
\hline \multicolumn{8}{|l|}{ Breastfeeding } \\
\hline Yes & No & $1.34(1.04-1.72)$ & 0.02 & $2.18(1.84-2.60)$ & $<0.01$ & $2.17(1.75-2.69)$ & $<0.01$ \\
\hline \multicolumn{8}{|l|}{ Region } \\
\hline Central & East & $1.20(0.96-1.50)$ & 0.10 & $1.21(0.99-1.47)$ & 0.07 & $1.63(1.25-2.13)$ & $<0.01$ \\
\hline West & East & $1.66(1.35-2.04)$ & $<0.01$ & $1.95(1.60-2.37)$ & $<0.01$ & $2.11(1.62-2.76)$ & $<0.01$ \\
\hline \multicolumn{8}{|l|}{$\begin{array}{c}\text { Mother's } \\
\text { education level }\end{array}$} \\
\hline High & Low & $0.77(0.63-0.95)$ & 0.01 & $0.58(0.47-0.72)$ & $<0.01$ & $0.70(0.51-0.95)$ & 0.02 \\
\hline \multicolumn{8}{|l|}{ Residence areas } \\
\hline SMC & $\mathrm{BC}$ & NS & & NS & & $1.80(1.30-2.50)$ & $<0.01$ \\
\hline OC & $\mathrm{BC}$ & & & & & $1.25(0.89-1.76)$ & 0.20 \\
\hline PC & $\mathrm{BC}$ & & & & & $1.31(0.90-1.90)$ & 0.15 \\
\hline \multicolumn{8}{|l|}{ MDD } \\
\hline Yes & No & NA & & NS & & $0.60(0.49-0.73)$ & $<0.01$ \\
\hline \multicolumn{8}{|l|}{ Mother's age } \\
\hline Older & Younger & NS & & NS & & $0.70(0.57-0.85)$ & $<0.01$ \\
\hline
\end{tabular}

NS: not significant; NA: not available. Note: the model of children aged 0-5 months adjusted for ethnicity, residence areas, maternal age, house toilet type, family income and Is formula-fed factors. The model of children aged 6-11 months adjusted for ethnicity, residence areas, maternal age, house toilet type, low birth weight, family income and iron-rich-food feeding factors. The model of children aged 12-23 months adjusted for ethnicity, residence areas, maternal age, house toilet type, low birth weight, family income and iron-rich-food feeding factors. The significant factors showed in bold.

For infants aged $6-11$ months, female sex (OR $=0.77 ; 95 \%$ CI: $0.66-0.90 ; p=0.00)$ and having a mother with a higher level of education (OR $=0.58 ; 95 \%$ CI: $0.47-0.72 ; p<0.01)$ were associated with lower odds of developing anaemia. As in the previous age group, premature birth ( $\mathrm{OR}=1.30 ; 95 \%$ CI: $1.01-1.67 ; p=0.04)$, breastfeeding $(\mathrm{OR}=2.18 ; 95 \%$ 
CI: $1.84-2.60 ; p<0.01)$ and residing in the Western region of China (OR $=1.95 ; 95 \% \mathrm{CI}$ : $1.60-2.37 ; p<0.01$ ) were associated with higher odds of developing anaemia.

For infants aged $12-23$ months, individuals who met the MDD $(\mathrm{OR}=0.60 ; 95 \% \mathrm{CI}$ : $0.49-0.73 ; p<0.01)$, those whose mother had a higher level of education $(\mathrm{OR}=0.70 ; 95 \%$ CI: $0.51-0.95 ; p=0.02$ ) and those whose mother had a maternal birth age of $>25$ years (OR $=0.70 ; 95 \%$ CI: $0.57-0.85 ; p<0.01)$ had lower odds of developing anaemia. In contrast, breastfeeding $(\mathrm{OR}=2.17 ; 95 \% \mathrm{CI}: 1.75-2.69 ; p<0.01)$, residing in small or middle-sized cities (OR $=1.80 ; 95 \%$ CI: $1.30-2.50 ; p<0.01)$ and living in the Central region of China (OR $=1.63 ; 95 \%$ CI: $1.25-2.13 ; p<0.01)$, living in the West region of China $(\mathrm{OR}=2.11 ; 95 \% \mathrm{CI}$ : $1.62-2.76 ; p<0.01$ )were associated with higher odds of developing anaemia.

\section{Discussion}

In this study, we determined the prevalence and distribution of anaemia in a nationally representative sample of Chinese infants aged 0-23 months. We found a substantial prevalence of anaemia among all infants aged 0-23 months: $22.15 \%$ were diagnosed with anaemia, of whom approximately $95.3 \%$ had mild anaemia, and $4.7 \%$ had moderate anaemia. The prevalence of anaemia among infants aged 0-23 months varied widely across provinces. Anaemia was more commonly seen in infants aged 6-11 months and in those living in the Western region. We also found that the risk factors associated with the prevalence of infantile anaemia were sex, maternal age, maternal educational level, premature birth, birth weight, breastfeeding and meeting MDD.

\subsection{Burden of Infantile Anaemia in China in 2013}

The prevalence of infantile anaemia observed in our study was lower than that among preschool children worldwide (47.4\%) [14], in Latin America and the Caribbean (32.9\%) [15] and in Africa (50.4-70.9\%) [16,17] but higher than that among children aged 6-59 months in Canada (9.4\%) and in the USA in 2013 (6.8\%) [18]. The WHO estimates that approximately 1.62 billion people worldwide suffer from anaemia, of whom 293 million are children of preschool age [14]. A previous study in the Shanxi Province of China reported that approximately $54.3 \%$ of infants aged $6-11$ months had anaemia and that $24.3 \%$ of infants in rural China had moderate or severe anaemia [19]. In addition, it revealed that the prevalence of anaemia was highest among infants aged 6-11 months, an age at which crucial developments in psychomotor skills occur.

\subsection{Distribution Map of Infantile Anaemia in China in 2013}

Based on the WHO classification system for anaemia prevalence [20], it is apparent that anaemia remains a severe public health problem in China. Approximately half of the study sites ( 27 out of 55 surveillance sites) had cases of moderate to severe anaemia among infants aged 0-23 months. The map of anaemia prevalence suggests that the prevalence of infantile anaemia is highest in the Western region, followed by the Central and Eastern regions. Our estimation of infantile anaemia prevalence at the regional and country level produced an important cartographic resource and provides important new evidence regarding sub-country-level priority areas for anaemia control.

\subsection{Factors Associated with the Prevalence of Anaemia in Chinese Infants Aged 0-23 Months}

Previous studies have demonstrated that socioeconomic status is a risk factor associated with the development of anaemia. Our study found that a higher level of maternal education and residence in economically developed areas were associated with lower odds of developing anaemia. This observation is in concordance with findings from Ghana [21], Guinea [22], India [23,24] and other studies in China [25]. Although the socioeconomic indicators for China (e.g., food expenditure, average disposable income and gross domestic product per capita) have increased in both urban and rural areas over the past decades [26,27], holistic socioeconomic conditions remain better in urban and Eastern/Central areas than in rural and Western areas [28]. The prevalence of infantile anaemia 
therefore remains higher in rural areas than in urban areas, although this difference is decreasing. Improving socioeconomic status may thus play an important role in reducing the prevalence of anaemia.

Many studies have demonstrated that maternal and reproductive health (e.g., premature birth, LBW, low maternal birth age) are associated with a higher risk of developing childhood anaemia $[23,29,30]$. Consistent with these results, our study showed that these risk factors were strongly associated with higher odds of developing anaemia among Chinese infants aged 0-23 months. This might be because infants with LBW are born with reduced iron stores [7], which play a pivotal role in the incidence of anaemia. In addition, younger mothers have less experience in caring for and rearing children than older mothers.

Our study also revealed that infant feeding is another important factor that is associated with the burden of infantile anaemia in China. We found that breast-fed infants were more likely to suffer from anaemia (OR: 1.34-2.18, $p<0.02$ ), which is consistent with a previous study of Chinese infants [25]. This can be ascribed to the specific characteristics of infants aged 6-11 months. After six months of age, the iron provided by breast milk is no longer sufficient to support the needs of infants. At this stage, supplementary food not given in a timely or reasonable manner may lead to iron deficiency and anaemia. Food supplementation is an important factor associated with the development of infantile anaemia, as reflected by the MDD. We found that meeting the MDD guidelines was associated with low odds of developing anaemia among infants aged 12-23 months, which is consistent with a previous study conducted in India [31].

According to a study, $>55 \%$ of children in East Asia have iron-deficiency anaemia (IDA) [32], and the proportion in China can be as high as $>80 \%$ [4]. Only if the anaemia was IDA were iron interventions effective in preventing anaemia [33]. Efforts should be made to reduce the prevalence of infant anaemia in China. Infant feeding is a key point to solving iron-deficiency anaemia personally. Scientific and reasonable complementary food addition include in time food addition and guarantee a variety of food. To the eliminate gap in different areas, complementary food fortification such as Ying Yang Bao (YYB) should implement in more rural areas and cover more children under 23 months because the YYB project greatly reduced the anaemia of children in poverty-stricken rural countries [34].

\subsection{Strengths and Limitations}

The strengths of this study lie in its large representative sample of Chinese infants. The CNHS (2010-2013) was a national surveillance and was implemented by National Institute for Nutrition and Health, Chinese Center for Disease Control and Prevention. All surveillance sites strictly followed the standardized protocols and data collection procedures. In addition, we collected information on a wide range of potential associated factors.

However, we should also acknowledge its limitations. First, the cross-sectional design of the study makes it difficult to evaluate temporal relationships of the associated factors with the prevalence of anaemia. Second, we could not exclude survivor bias, as only surviving infants were included. However, infants may have died from anaemia. Without the additional quantification of iron and inflammatory biomarkers (e.g., ferritin, sTfR, CRP, AGP), the analysis is unable to reveal how much of the anaemia burden is due to iron deficiency and how much would be expected to be responsive to iron interventions (e.g., distinguishing absolute iron deficiency vs. functional iron deficiency, the latter of which may not be responsive to simple oral iron interventions). Information such as this, in order to better understand the aetiology of the anaemia across the different regions, would be very valuable and desirable to obtain through future related studies. Third, the data were collected in 2013, which was relatively old. In the past decade, the YYB project was implemented in poor rural areas and improved the anaemia status of infants in these areas; in the future, based on new data, more socioeconomic and environmental factors should be used to analyse the prevalence of childhood anaemia. 


\section{Conclusions}

The prevalence of anaemia among Chinese infants aged 0-23 months in 2013 was significantly high. China has experienced widening disparities in the prevalence of anaemia across regions, with a persistent disparity between urban and rural areas. Our results show that male sex, lower maternal educational level, younger maternal birth age, premature birth, LBW, breastfeeding and lack of compliance to MDD guidelines are significantly associated with higher odds of infants aged 0-23 months developing anaemia.

Author Contributions: S.L. conducted data analysis and drafted the manuscript. Y.B. and X.L. revised the manuscript critically. H.R. and C.Z. helped process the data. L.Z. participated in project design and implementation and contributed significantly to data acquisition. D.Y. helped with interpretation of data and revised the manuscript critically. All authors have read and agreed to the published version of the manuscript.

Funding: This research was supported by a grant from the State Key Laboratory of Resources and Environmental Information System.

Institutional Review Board Statement: The study was conducted according to the guidelines of the Declaration of Helsinki, and approved by the Ethics Committee of the National Institute for Nutrition and Food Safety of the Chinese Centre for Disease Control and Prevention (protocol code 2013-018 and 15 March 2013).

Informed Consent Statement: Informed consent was obtained from all subjects involved in the study.

Data Availability Statement: The data is not allowed to disclose according to the National Institute for Nutrition and Health, Chinese Center for Disease Control and Prevention.

Acknowledgments: We thank all the staff from province/city/county level Center for Disease Control and Prevention who participated in the investigation and all of the participants in CNHS 2013 for their contribution and support.

Conflicts of Interest: This manuscript is an original work and has not been published elsewhere. None of the authors have any conflicts of interest.

\section{References}

1. Vitamin and Mineral Nutrition Information System. Available online: https://www.who.int/vmnis/database/anaemia/ anaemia_status_summary/en/ (accessed on 10 December 2020).

2. Grantham-McGregor, S. Early child development in developing countries. Lancet 2007, 369, 824. [CrossRef]

3. Lozoff, B.; Jimenez, E.; Hagen, J.; Mollen, E.; Wolf, A.W. Poorer behavioral and developmental outcome more than 10 years after treatment for iron deficiency in infancy. Pediatrics 2000, 105, E51. [CrossRef]

4. Huang, Y.; Wang, L.; Huo, J.; Wu, Q.; Zhang, Y. Prevalence and causes of anaemia in children aged 6-23 months in rural Qinghai, China: Findings from a cross-sectional study. BMJ Open 2019, 9, e031021. [CrossRef]

5. Lei, W.; Yonglei, S.; Buyao, L.; Lijuan, Z.; Mengiie, L. Is Infant/Toddler Anemia a Problem across Rural China? A Mixed-Methods Analysis. Int. J. Environ. Res. Public Health 2018, 15, 1825.

6. Nie, J.; Yang, J.; Zhang, L.; Li, Y.; Yang, J. Current Status and Influencing Factors of Infant Anemia in Poor Rural Areas of Western China. J. East. China Norm. Univ. (Educ. Sci.) 2019, 37, 58-69.

7. Balarajan, Y.; Ramakrishnan, U.; Ozaltin, E.; Shankar, A.H.; Subramanian, S.V. Anaemia in low-income and middle-income countries. Lancet 2011, 378, 2123-2135. [CrossRef]

8. Guo, Q.; Yu, D.; Yu, D.; Wang, X.; Xu, X.; Fang, Y.; YU, W.; Jia, F.; Zhao, L. Comparative analysis of China Nutrition and Health Surveillance/Survey in 1959, 1982, 1992, 2002 and 2010-2013. J. Hyg. Res. 2016, $45,7$.

9. Sun, Y.; Duan, J.; Teng, L.; Zhao, H. Comparative analysis of dry chemistry method and cyanmethemoglobin in detecting hemoglobin. Chin. J. Health Lab. Techinology 2015, 25, 3.

10. Sullivan, K.M.; Mei, Z.; Grummer-Strawn, L.; Parvanta, I. Haemoglobin adjustments to define anaemia. Trop. Med. Int. Health 2008, 13, 1267-1271. [CrossRef] [PubMed]

11. China, N.B.o.S.o. Code for Statistical Division and Code for Urban Rural Division in 2012. Available online: http:/ / www.stats. gov.cn/tjsj/tjbz/tjyqhdmhcxhfdm/2012/index.html (accessed on 12 December 2020).

12. China, N.H.a.F.P.C.o.t.P.s.R.o. China Health Statistics Yearbook 2013. Available online: http://www.nhc.gov.cn/htmlfiles/ zwgkzt/ptjnj/year2013/index2013.html (accessed on 12 December 2020).

13. WHO. Haemoglobin Concentrations for the Diagnosis of Anaemia and Assessment of Severity. Vitamin and Mineral Nutrition Information System. Available online: http://www.who.int/vmnis/indicators/haemoglobin.pdf (accessed on 10 January 2021). 
14. Chen, L.; Li, Y.; Li, Y.; Yang, F.; Bi, X. Iron deficiency anemia status and influencing factors among children aged 6 23 months in rural minority areas in Yunnan. Chin. J. Child. Health Care 2017, 25, 3.

15. Iglesias Vázquez, L.; Valera, E.; Villalobos, M.; Tous, M.; Arija, V. Prevalence of Anemia in Children from Latin America and the Caribbean and Effectiveness of Nutritional Interventions: Systematic Review and Meta-Analysis. Nutrients 2019, 11, 183. [CrossRef]

16. Nambiema, A.; Robert, A.; Yaya, I. Prevalence and risk factors of anemia in children aged from 6 to 59 months in Togo: Analysis from Togo demographic and health survey data, 2013-2014. BMC Public Health 2019, 19, 215. [CrossRef]

17. Petry, N.; Jallow, B.; Sawo, Y.; Darboe, M.K.; Barrow, S.; Sarr, A.; Ceesay, P.O.; Fofana, M.N.; Prentice, A.M.; Wegmüller, R.; et al. Micronutrient Deficiencies, Nutritional Status and the Determinants of Anemia in Children 0-59 Months of Age and Non-Pregnant Women of Reproductive Age in The Gambia. Nutrients 2019, 11, 2275. [CrossRef] [PubMed]

18. World Health Organization. Prevalence of Anaemia in Children Under 5. Available online: https://apps.who.int/gho/data/ view.main.ANEMIACHILDRENv (accessed on 20 January 2021).

19. Luo, R.; Shi, Y.; Zhou, H.; Yue, A.; Zhang, L.; Sylvia, S.; Medina, A.; Rozelle, S. Anemia and feeding practices among infants in rural Shaanxi Province in China. Nutrients 2014, 6, 5975-5991. [CrossRef] [PubMed]

20. DeMaeyer, E.M.; Dallman, P.; Gurney, J.M.; Hallberg, L.; Sood, S.K.; Srikantia, S.G.; World Health Organization. Iron Deficiency Anaemia Assessment, Prevention, and Control A Guide for Programme Managers; World Health Organization: Geneva, Switzerland, 1989.

21. Shenton, L.M.; Jones, A.D.; Wilson, M.L. Factors Associated with Anemia Status Among Children Aged 6-59 months in Ghana, 2003-2014. Matern. Child Health J. 2020, 24, 483-502. [CrossRef]

22. Ncogo, P.; Romay-Barja, M.; Benito, A.; Aparicio, P.; Nseng, G.; Berzosa, P.; Santana-Morales, M.A.; Riloha, M.; Valladares, B.; Herrador, Z. Prevalence of anemia and associated factors in children living in urban and rural settings from Bata District, Equatorial Guinea, 2013. PLoS ONE 2017, 12, e0176613. [CrossRef] [PubMed]

23. Thomas, M.S.; Demirchyan, A.; Khachadourian, V. How Effective Is Iron Supplementation During Pregnancy and Childhood in Reducing Anemia Among 6-59 Months Old Children in India? Front. Public Health 2020, 8, 234. [CrossRef] [PubMed]

24. Phuong Hong, N.; Samuel, S.; Rasmi, A.; Lan Mai, T.; Menon, P. Trends and drivers of change in the prevalence of anaemia among 1 million women and children in India, 2006 to 2016. BMJ Glob. Health 2018, 1, 3.

25. Qian-Qian, X.; Bo-Wen, C.; De-Lu, Y.; Feng, X.; Rui-Li, L.; Tao, Y.; Hui-Min, Y.; Xiao-Guo, Z.; Li-Hong, W. Prevalence of Anemia and its Risk Factors among Children under 36 Months Old in China. J. Trop. Pediatrics 2016, 63.

26. National Bureau of Statistics of China. 3-1 Gross Domestic Product. Available online: http://www.stats.gov.cn/english/ statisticaldata/Quarterlydata/index.html (accessed on 22 January 2021).

27. National Bureau of Statistics of China. People's Living Conditions. Available online: http://www.stats.gov.cn/english/ statisticaldata/Quarterlydata/index.html (accessed on 22 January 2021).

28. National Bureau of Statistics of China. Available online: http://www.stats.gov.cn/tjsj/ndsj/2019/indexeh.htm (accessed on 22 January 2021).

29. Saito-Benz, M.; Flanagan, P.; Berry, M.J. Management of anaemia in pre-term infants. Br. Haematol. 2020, 188, 354-366. [CrossRef]

30. Asresie, M.B.; Fekadu, G.A.; Dagnew, G.W. Determinants of Anemia among Children Aged 6-59 Months in Ethiopia: Further Analysis of the 2016 Ethiopian Demographic Health Survey. Adv. Public Health 2020, 4, 1-6. [CrossRef]

31. Gosdin, L.; Martorell, R.; Bartolini, R.M.; Mehta, R.; Young, M.F. The co-occurrence of anaemia and stunting in young children. Matern. Child. Nutr. 2018, 14, e12597. [CrossRef] [PubMed]

32. Stevens, G.A.; Finucane, M.M.; De-Regil, L.M.; Paciorek, C.J.; Flaxman, S.R.; Branca, F.; Peña-Rosas, J.P.; Bhutta, Z.A.; Ezzati, M.; Nutrition Impact Model Study Group. Global, regional, and national trends in haemoglobin concentration and prevalence of total and severe anaemia in children and pregnant and non-pregnant women for 1995-2011: A systematic analysis of population-representative data. Lancet Glob. Health 2013, 1, e16-e25. [CrossRef]

33. Pasricha, S.R.; Armitage, A.E.; Prentice, A.M.; Drakesmith, H. Reducing anaemia in low income countries: Control of infection is essential. BMJ 2018, 362, k3165. [CrossRef] [PubMed]

34. Huo, J.; Sun, J.; Fang, Z.; Chang, S.; Zhao, L.; Fu, P.; Wang, J.; Huang, J.; Wang, L.; Begin, F. Effect of Home-Based Complementary Food Fortification on Prevalence of Anemia Among Infants and Young Children Aged 6 to 23 Months in Poor Rural Regions of China. Food Nutr. Bull. 2015, 36, 405-414. [CrossRef] 